\title{
The Solanum nigrum Complex (Black Night Shade) Grown in the Rift Valley, Western and Nyanza Provinces of Kenya
}

\author{
Lexa Gomezgani Matasyoh and Asa Nyang’au. Bosire \\ University of Eldoret/Biological Science Department, Eldoret, Kenya
}

\begin{abstract}
Solanum nigrum complex comprises of plant species that belong to Solanum section Solanum used as indigenous leafy vegetables in Kenya among many communities. The Solanum nigrum complex species have also been used traditionally as medicine. Many species make up the Solanum nigrum complex, and some include S. scabrum, S. villosum, S. americanum, S. nigrum, S. americanum, and S. physalifolium. The purpose of this study was to determine the species of Solanum nigrum complex found in Rift Valley, Nyanza and Western provinces of Kenya. Samples were collected from Eldoret-Iten, Kisumu-Nyando, Kisii-Nyamira, Nakuru, and Busia then pressed and sent to a plant taxonomist in Egerton University for classification and identification. It was established that the collected samples belonged to S. nigrum, S. scabrum, and S. villosum species. The morphological characteristics used to distinguish the species included shape and colour of the stems, size and shape of the leaves, size, shape and colour of the berries, and the inflorescence. S. nigrum was widely found in some regions with a noticeable bias towards $S$. scabrum that was preferred due to its large size of leaves and taste when cooked. However, the distribution and presence of S. nigrum and S. villosum in some of the study regions was poor.
\end{abstract}

Key words: Solanum nigrum complex, S. scabrum, S. villosum, S. nigrum.

\section{Introduction}

Solanum nigrum complex comprises of plant species that belong to Solanum section Solanum used as indigenous leafy vegetables in Kenya among many communities. The Solanum nigrum complex species have also been used traditionally as medicine. Many species make up the Solanum nigrum complex, and some include S. scabrum, S. villosum, S. americanum, S. nigrum, S. americanum, and S. Physalifolium. Manoko [1] identified nine African species, while Maundu et al. [2] identified five nightshade species considered common in Kenya. They include: Solanum physalifolium, Solanum villosum Miller, Solanum nigrum L., Solanum scabrum Miller, and Solanum americanum Miller. The genus Solanum is large and contains other groups with Solanum nigrum L. being

Corresponding author: Lexa Gomezgani Matasyoh, Ph.D., research field: molecular population genetics. the most variable group. African nightshades are among the indigenous plant species used as leafy vegetables in Kenya [3] that continue to be cultivated by many Kenyan communities. The Solanum species do display varying amounts of phenotypic variation, mainly in their vegetative features such as stem winging, leaf size and shape, and plant habit. Usually, senescence occurs with fewer and smaller fruits and flowers with a variation in the pigmentation of the flowers [4]. They are nutritionally rich in calcium, iron, and vitamins A and C [5]. Solanum nigrum which is a synonym of Solanum villosum is believed to have originated in Eurasia, is widespread and found in Africa e.g. Kenya. Leaves and young shoots of sparsely hairy types of Solanum nigrum are used as a leafy vegetable and form an important part of traditional medicine in Africa. In Kenya, unripe fruits soothe toothache, and are squeezed on babies' gums to ease pain during the early stages of teething to ease 
pain. Leaves are used to treat stomachache and extracts from leaves and fruits are used to treat tonsillitis. They are, however, also widely used as leafy herbs and vegetables, as a source of fruit and for various medicinal purposes to treat ailments such as Malaria, stomach ache, colds and coughs, high blood pressure, diabetes, chest pains [6]. The plant is also used in the oriental systems of medicine for various purposes-as an antitumorigenic, antioxidant, anti-inflammatory, hepatoprotective, diuretic, and antipyretic agent [7]. The purpose of this study was to determine the species of Solanum nigrum complex found in Rift Valley, Nyanza and Western provinces of Kenya.

\section{Materials and Methods}

\subsection{Study Area}

Samples were collected from Eldoret-Iten, Kisumu-Nyando, Kisii-Nyamira, Nakuru, and Busia. The collected samples were pressed, and sent to a plant taxonomist in Egerton University for classification and identification.

\subsection{Sample Collection}

A consultation survey was carried out in the study areas where agricultural extension officers were used to provide knowledge on the Solanum nigrum complex species grown in the region. However, the market vendors commonly and locally known as "mama mboga" proved vital in providing the necessary information on the available species. They majorly referred to the species using two terms: "Kienyeji", which is a local word that means Indigenous, and is used to refer to the Indigenous species, and "Agriculture" which is a term used to refer to the improved varieties that they get seeds in the agricultural stores. All the available samples in all the areas were collected, and labeled immediately using the local names pending identification. Pressed samples were taken to a taxonomist at Egerton University for identification. Clear photos and berries taken from the field proved important in carrying out classification of the samples.

\subsection{Morphology Descriptor List}

A morphology descriptor list was made and developed using the morphological features described by [4]. The variations observed were used to revise the descriptor list in order to cover all the plant samples collected in all the study areas. Morphological characteristics were scored using the final version of the descriptor list. A magnifier was used to differentiate the hair-types. The morphological characteristics were observed at various points that included whole plants, stems, leaves, fruiting pedicel, inflorescence, flowers, corolla, anthers, styles, sepals and berries.

\section{Results and Discussion}

The eleven populations of samples collected were narrowed down and classified into three different species namely S. villosum, S. nigrum, and S. scabrum. General morphological characteristics like colour of ripe berries, leaf size and shape helped to group the samples into general groups. The $S$. scabrum species is morphologically characterized with broad leaves, with its ripe seeds being black in colour but differ in size from the $S$. nigrum Mill berries, which are smaller [8]. In Busia, S. scabrum was popular with the locals due to its large size of leaves and lack of the bitter taste. However, it was noted that its seeds were readily available in the agricultural stores. S. scabrum had presence in all the study areas except Kisii-Nyamira where the locals prefer to use $S$. villosum and $S$. nigrum Mill. S. nigrum is an indigenous variety that grows naturally in Nyamira, Busia, and Nakuru. It is characterized with its bitter taste. In Nakuru, it usually grows in the wheat and maize plantations. Both the locals in Nyamira and Busia consider the bitter $S$. nigrum to posses' medicinal value. The locals in the Kisii community believe that it cures malaria and this justified the findings reported by [9]. In Eldoret-Iten, 
S. villosum has popularity and its consumption is high compared to $S$. scabrum that is also available. $S$. villosum was characterized by its less bitter taste when cooked. The leaves for this species appeared to have a serrated margin. Majority of the locals, who are the Kalenjin speaking, do not have knowledge of $S$. nigrum and therefore they do not plant it. Farmers have done extensive farming of $S$. villosum variety although S. scabrum is scantily planted. There was no evidence to point out the availability of naturally growing varieties in Eldoret-Iten. Farmers, who acquired the seeds from the agricultural stores, grew the two species. In Kisumu-Nyando, S. nigrum and $S$. scabrum were the popular varieties with $S$. villosum lacking. The seeds for S. nigrum and S. scabrum were not edible unlike $S$. villosum which were edible. The colour and size of the berries was a major distinguishing feature. S. villosum has orange berries while $S$. nigrum and $S$. scabrum both have black to purple berries, which differ in size. S. nigrum berries are small $(8-11 \mathrm{~mm})$ while $S$. scabrum berries are large (16-20 mm).

\subsection{S. nigrum Complex Morphological Characteristics}

S. villosum: Whole plants: grows up to $1.3 \mathrm{~m}$ high with hard spreading branches. Stem: green in colour with dark purplish nodes; internodes measure up to 70-100 mm; short hairs are present. Leaves: both small and medium sized, ovate with smooth margins with some serrated; green in colour with light green, networked veins; short erect hairs present on the surface. Fruiting pedicel: longer, reflexed. Inflorescence: 3-4 flowers, simple and cymose. Flowers: 9-11 mm; corolla: white; anthers: yellow and somehow conspicuous; sepals: green, ovate and reflexed away from berry. Berries: 9-10 mm, orange, globose and remains attached to the plant when ripe.

S. nigrum: whole plant: grows up to $1 \mathrm{~m}$ high with wide spreading branches. Stems: purple stems, purple nodes, internodes measure up to $65-90 \mathrm{~mm}$. Leaves: ovate with smooth margins, pointed apex, dark green

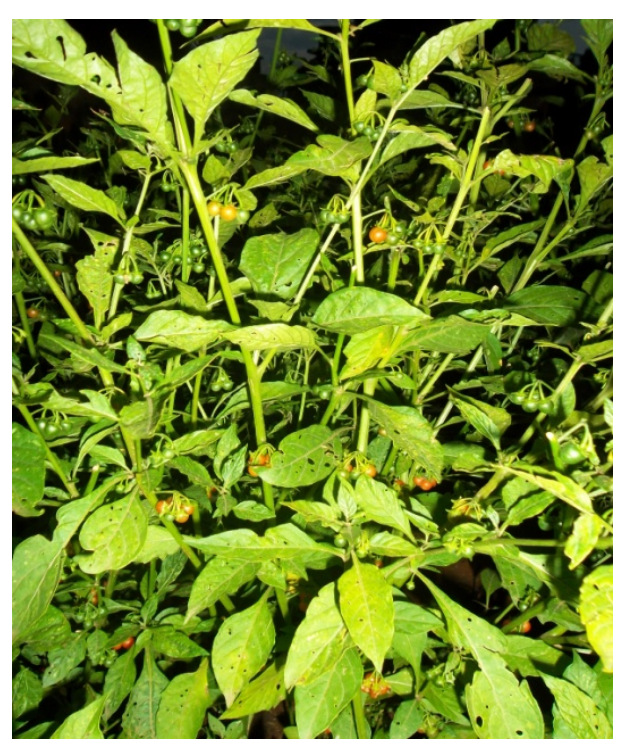

Fig. 1 S. villosum.

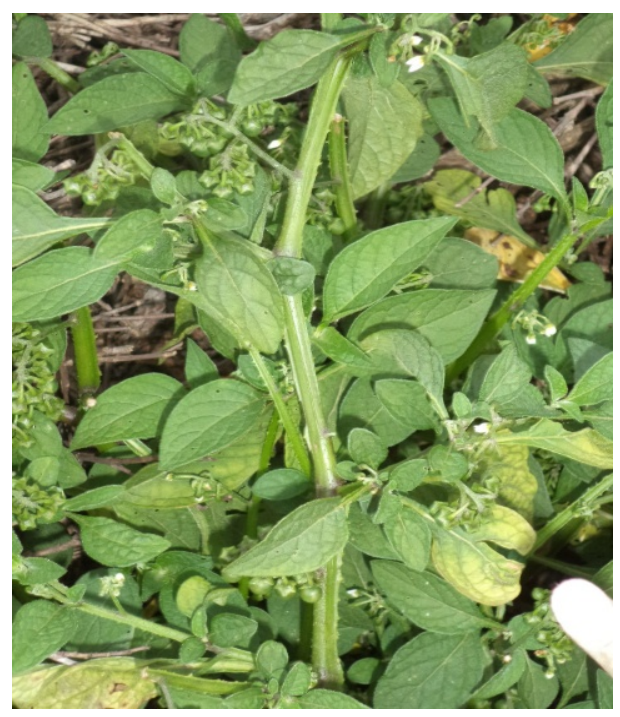

Fig. 2 S. nigrum.

in colour with purple-networked veins, short hair seen with bare eyes on underside. Fruiting peduncle: faces upward. Fruiting pedicel: reflexed. Inflorescence: mixture of cymes and forked cymes on same plant, 7-10 flowers. Flowers: 10-14 mm; Corolla: white and fused at the base; anthers: yellow; sepals: triangular ovate reflexed away from the berry but occasionally adherent. Berries: 8-11 mm, purple to black and remain stuck on plant when ripe.

S. scabrum: whole plant: erect with lateral branches spreading horizontally. Stems: highly winged (dented) and succulent, green to purplish green, glabrous (no 


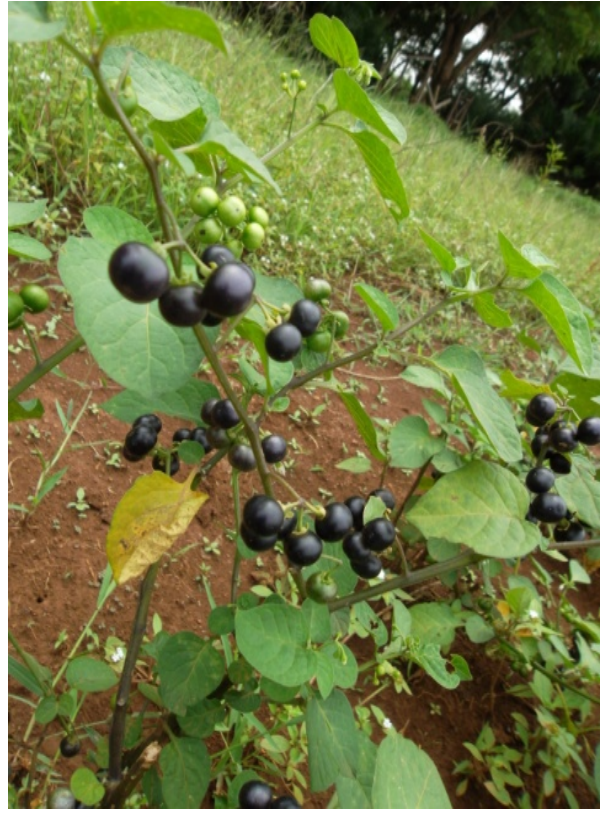

Fig. 3 S. scabrum.

hair), internodes measure up to $80 \mathrm{~mm}$. Leaves: ovate, wide and large, smooth entire margins, green to dark green in colour, green to purple vein colour and networked. Fruiting peduncle: faces upward. Fruiting pedicel: reflexed or erect. Inflorescence: cymose, many flowered. Flowers: showed variations in colour, white, others purple with a yellow basal star. Sepals: reflexed away from mature berry. Berries: ovoid and broad, $16-20 \mathrm{~mm}$ in diameter, purplish in colour, shiny, and remains on plant when ripe.

\section{Conclusions and Recommendation}

The research study revealed that there are three species of the Solanum nigrum complex found in the rift valley, western, and Nyanza provinces of Kenya. There were variations of the species that are cultivated in the different provinces largely influenced by the taste, economic reasons, and sensitization by agricultural extension officers. In some areas, some variants were preferred more than the others were. Mostly, those who considered it to have medicinal value preferred $S$. nigrum. It is recommended that more research be carried out to determine why some variants are not available in some areas for example in Eldoret-Iten where only S. scabrum and S. villosum are cultivated. The fact that in some areas farmers depend on commercially available seeds raises questions if whether Solanum nigrum complex species were introduced into that area. This is yet to be determined through more research.

\section{Acknowledgments}

The author wishes to acknowledge the support given by the National Commission for Science, Technology and Innovation through funding of the project. The author is thankful to the vegetable vendors and agricultural extension officers who were vital in providing information at county level, the farmers who provided samples for their cooperation.

\section{References}

[1] Manoko, M. L. K. 2007. A Systematic Study of African Solanum L. Section Solanum (Solanaceae) (Doctoral dissertation, Ph.D. thesis: Radboud Univesity Nijmegen).

[2] Maundu, P. M., Ngugi, G. W., and Kabuye, C. H. S. 1999. “Traditional Food Plants of Kenya." Kenya Resource Center for Indigenous Knowledge: National Museums of Kenya, 210-1.

[3] Gockowski, J., Mbaso, O. J., Mbah, G., and Moulende, T. F. 2003. "African Traditional Leafy Vegetables and the Urban and Peri Urban Poor.” Food Policy 28: 221-35. doi:10.1016/S0306-9192(03)00029-0.

[4] Edmonds, J. M., and Chweya, J. A. 1997. Black Nightshades. Solanum nigrum L. and related species. Promoting the conservation and use of underutilized and neglected crops, (15). Institute of Plant Genetics and Crop Plant Research, Gatersleben/International Plant Genetic Resources Institute, Rome, Italy.

[5] Schippers, R., Maundu, P. M., Mbuni, M., and Obiero, H. 2001. How to Grow and Use African Nightshades. Kenya Resource Center for Indigenous Knowledge (KENRIK) National Museums of Kenya, 3-7, Nairobi, Kenya.

[6] Kimiywe, J., Waudo, J., Mbithe, D., and Maundu, P. 2007. "Utilization and Medicinal Value of Indigenous Leafy Vegetables Consumed in Urban and Peri-urban Nairobi.” African Journal of Food, Agriculture, Nutrition and Development 7 (3 and 4).

[7] Zakaria, Z. A., Gopalan, H. K., Zainal, H., Mohd Pojan, N. H., Morsid, N. A., Aris, A., and Sulaiman, M. R. 2006. "Antinociceptive, Anti-inflammatory and Antipyretic Effects of Solanum nigrum Chloroform Extract in Animal Models." Journal of the Pharmaceutical Society of Japan 126 (11): 1171-8. doi:10.1248/yakushi.126.1171. 
Western and Nyanza Provinces of Kenya

[8] Olet, E. A., Manfred, H., and Kare, A. 2005. “African Crop or Poisonous Nightshade; the Enigma of Poisonous or Edible Black Nightshade Solved.” African Journal of Ecology 43:

2 , doi:10.1111/j.1365-2028.2005.00556.x.
[9] Nyarango, R. M., Aloo, P. A., Kabiru, E. W., and Nyanchongi, B. O. 2008. "The Risk of Pathogenic Intestinal Parasite Infections in Kisii Municipality, Kenya.” BMC Public Health 8 (1): 237. doi:10.1186/1471-2458-8-237. 